\title{
Episodic -ee in English: Thematic relations and new word formation
}

\author{
Chris Barker \\ University of California, San Diego
}

This paper approaches the topic of thematic relations through a case study of the English suffix -ee, as in employee, escapee, and refugee. The data suggest that $-e e$ is highly productive (section 1), that analyses based on the syntactic argument structure of the stem are incomplete or highly disjunctive (section 2), and that formation of nouns in -ee systematically adheres to threeessentially semantic constraints: first, the referent of an -ee noun must be sentient (as often noted before, e.g., Bengtsson (1927:79); see section 3). Second, the denotation of an -ee noun must be episodically linked to that of its stem (see section 4 for a formal semantic event-based definition of "episodically linked"). Third, a use of an -ee noun entails a lack of volitional control on the part of its referent. This last constraint as developed more precisely below (see section 5) takes seriously the common references to -ee as a 'patient' suffix and elaborates on Horn's (1980:142) claim that "the animate -ee nominal is presented as helpless or relatively powerless". Taken together, these semantic constraints amount to a kind of thematic relation similar in many ways to traditional verbal thematic relations such as Agent or Patient. Thus thematic relations, or something very much like them, can actively constrain application of a moderately productive morphological process.

\section{Introduction}

This study is part of a broader investigation into the thematic relations of nouns and nominal expressions. Barker and Dowty (1992) propose that argument selection in underived nouns motivates postulating a set of thematic relations which is parallel to but distinct from the verbal system. In order to extend this work towards a more complete picture of nominal thematic relations, of course, it is necessary to also consider derived nouns, as in this paper. The null hypothesis is that the argument structure of the derived form is some more or less systematic function of the syntactic argument structure of the stem, perhaps constrained by certain general principles (see e.g., Chomsky (1970), Rappaport (1983), Grimshaw (1990)). However, if the analysis of $-e e$ defended here is correct, then the argument structure for a deverbal derived noun does not necessarily depend on the syntactic argument structure of its verbal stem at all; that is, the analysis defended here suggests that each derivational

Thanks to Greg Carlson, David Dowty, Peter Lasersohn, and Beth Levin for discussions and advice. Thanks to Jane Edwards and Gregory Grefenstette for helping me search electronic corpora. All -ee nouns mentioned in this paper have attested uses in naturally occurring text. Sources of much of the data appearing in this paper can be found by looking for the relevant -ee word in the second edition of the OED. A more complete version of the paper, including detailed sources for data not appearing in the OED, can be obtained by emailing the author at barker@ling.ucsd.edu. 
morpheme can potentially contribute its own idiosyncratic thematic argument selection requirements which ignore the syntactic argument structure associated with the stem and which depend instead primarily or entirely directly on the stem's meaning.

The main descriptive problem addressed in this paper can be thought of as determining the argument selection properties of the suffix -ee. Consider an event in which someone presents something to someone else. There are three entities prominently involved in such events: the person doing the presenting, the entity presented, and the person to whom the item is presented. What controls which of these three entities can be referred to using the -ee noun presentee? That is, which of these participants will the -ee noun select as its main argument? A purely syntactic approach would claim that the argument selection of presentee depends in some way on the syntactic argument structure of its stem verb present. I will argue that a better explanation can be constructed on the assumption that the argument selection of -ee nouns is constrained primarily by semantic properties of the entities involved in the relevant event.

The suffix -ee first came into common use under the influence of French in legal parlance during the 16 th century. Words in -ee are still a distinctive feature of legal diction, but most -ee word types are not legal in origin, including some of the most common forms such as employee, refugee, nominee, etc. The suffix is a naturalized version of the feminine form of the French past participle suffix ( $-e$ masculine and -ée feminine). In French, the past participle can also be used as a substantive to refer to the direct object participant of the stem verb: thus AF. apelé( $(e)$ can be used as a noun parallel to English appellee (first attested use in English given in the OED as 1531). From the first, however, the English suffix had its own distinctive properties; most notably, unlike its French source, the English suffix could be used to refer to indirect object participants. Jespersen (1905:111) cites vendee (1547) 'the person to whom a thing is sold; the purchaser', which in French would be l'homme á qui on a vendu quelquechose, and certainly not *le vendé.

A few non-legal examples that I hope are representative will give an impression of how the suffix is used in natural texts:

(1) 1593 They could witnesse the behauiour of the electees to be sincere.

(2) 1841 The family...are too nearly connected with the biographee.

(3) 1871 For the baptist to touch the head of the baptisee with the water.

(4) $1890 \mathrm{~A}$ second trial is made to test the length of time during which the experimentee can maintain his previous grip.

(5) 1894 The United States Senate yesterday returned the Tariff Bill to the Conference Committee without giving the Senate conferees any instructions.

(6) 1918 It is being considered... whether the dilutee should be discharged to provide for the re-entry of the skilled worker who has been to the war.

(7) 1939 Mrs. Miniver...will cope in a wonderful manner with refractory billetees.

(8) 1939 The Milesian deportees were settled at the mouth of the River Tigris.

(9) 1946 A highly organized and regimented society...is felt by the planners, and even...by the plannees to be more 'scientific', and therefore better, than...

(10) $1952 \mathrm{He}$ was feeling more than half tempted to take the letter over to the main hall and post it on the faculty bulletin board, before the arrival of the eleveno'clock tutee. 
(11) 1963 Widow of two of Stalin's purgees, Grigori Sokolnikov and L. P. Serebriakov, Serebriakova herself spent a decade in prison.

(12) 1965 The government can no longer prevent the restrictees from receiving visitors at will and today there is a constant stream on the trains.

(13) 1967 The neo-Nazi NPD party has probably rendered a service in drawing off the hard-core expellees.

(14) 1971 Elsewhere in the motel-we learn later-the rival corporation, Penta, has chosen a more ingenious method: they tell their mergees that it seems important only that the change be comfortable for everyone.

(15) 1973 the only resignee that $\mathrm{Mr}$ Nixon chose to criticize

(16) 1983 The number of potential enrollees with background in both [linguistics and computer science] was very small.

(17) 1987 Now I must edit myself. Actually it has been many years since I considered my prose inviolable, and even as an editee I now consider editing a good and necessary thing.

(18) 1989 "The 'battered woman' syndrome applies also to other types of violence or abuse within a household," Cleary says. The thread, he says, is physical and/or mental domination "in which the abusee develops almost a total dependence on the abusor."

(19) 1989 We explain to the arrestee that we intend to use a come-along hold that will cause pressure and probable pain if there is resistance...

(20) 1989 It is so very important to understand the difference between an immigrant, an asylee, a refugee and an illegal immigrant.

(21) 1989 Among the nine or so leech compounds under study are an anticoagulant (which the leech uses to keep the blood from clotting when it bites), a local anesthetic (which prevents the bitee from knowing the leech is there)...

\section{Productivity}

Many authors have noted the productivity of $-e e$, including Jespersen (1905:111), Onions (1943:6), Person (1958), Marchand (1969:268), Barnhart et al. (1990:152), and Bauer (1983:244, 1987:315, 1993). Furthermore, $-e e$ is highly productive by any quantitative measure I am aware of. By the count of Bengtsson (1927, presented in a table in the rear matter), the progressively increasing number of new uses counted per century are 2 in the 14 th; 11 in the 15 th; 21 in the 16 th; 26 in the 17th; 30 in the 18 th; and 100 in the 19 th, for a total of 190 attested word types by 1900 . Since then, by my count there are 196 word types whose earliest known date of occurrence is after 1900, 132 of which are later than 1950.

Though persuasive, counts of attested uses are not necessarily sound indications of productivity. For one thing, the number of attested uses depends strongly on the size of the corpus surveyed; as suggested by Onions, the longer you look, the more you find. Thus it is possible that much of the apparent increase in recent times is due to increasingly broad and accurate reporting of uses. Because of this concern, other quantitative measures of productivity should be considered.

Aronoff (1976) proposes that the productivity of a suffix should be measured by the ratio of attested forms to possible forms. That is, if there were a thousand distinct verbs suitable to serve as stems for -ee nouns, and 100 observed distinct uses 
of $-e e$, then the productivity index for $-e e$ would be $1: 10$. One difficulty pointed out by Baayen and Lieber (1991) with this measure is that it is strongly dependent on how the class of possible stems is characterized. Baayen and Lieber go on to further criticize Aronoff's measure on other grounds, and propose their own measure of productivity. On their proposal, the productivity of an affix is calculated relative to a fixed corpus by counting what they call hapaxes: word types for which there is exactly one instance in the corpus. Their productivity index is the ratio of hapaxes to the total number of tokens formed from the affix in question. Baayen and Lieber interpret this number as an estimate of the probability that the next instance of the affix in question will be a hapax. This in turn is supposed to approximate the likelihood of encountering a novel formation, which they consider to be the essence of productivity.

Based on a mixed corpus of 18 million words, Baayen and Lieber report that out of 1213 tokens of -ee words, 2 were hapaxes, giving a productivity index of 0.0016. Of the suffixes they investigated, only four had comparable or higher productivity indices: -ness as in kindness, 0.0044 ; -ish as in manish, 0.0034 ; -ian as in civilian, 0.0040 , and de-as in delouse, 0.0016. All of the other 26 affixes they considered had indicies less than half as great, including-able,-ity, -ation,-ous, -ment, un-, in-, etc. In particular, although -er (which they describe as "the agentive/instrumental suffix") has a much higher number of hapaxes (40, exceeded only by-ation and -ness), it also has a much higher total number of tokens $(57,683)$, resulting in a productivity index of 0.0007 , roughly half that of $-e e$.

For a second measurement, a computerized survey of roughly five hundred megabytes of text from recent Wall Street Journal and Associated Press articles gives an estimated productivity index of 0.0022 for -ee. Since the size of this corpus is significantly larger than the corpus used by Baayen and Lieber, direct comparison is not valid. Nevertheless, the fact that this estimate is at least in the same ballpark does justify some measure of confidence in the index calculated by Baayen and Lieber. More specifically, recall that their measurement depended on only two hapaxes, a small number. For the larger corpus considered here, there are twenty hapaxes. Furthermore, these forms are by and large not at all well-established, and thus provide a reasonable approximation of productive use of $-e e$ as they stand (word types preceded by a bullet $(\bullet)$ have not been previously attested, and are especially likely to constitute a productive use): abusee, $\bullet$ acquiree, advisee, arrivee, assignee, bailee, beatee, •bitee, dedicatee, •ejectee, •financee, •firee ['person fired from a job'], insuree, invitee, mergee, murderee, offeree ['person to whom an offer is made'], •optionee ['buyer'], •politico-politicee, and retrainee.

In summary, although -ee is substantially less productive than fully productive suffixes such as -ing or - $l y$, when it is compared to other less than fully productive affixes, the data show that $-e e$ is clearly highly productive.

\section{Against a purely syntactic explanation}

Previous analyses characterize -ee variously as "passive" (most notably Bengtsson (1927)), as unaccusative (Horn (1980)), as absolutive (commonly heard, but rarely seen in print; see for instance the tentative suggestion due to Bernard Comrie as quoted in Bauer (1983:250)), or as multiply ambiguous (Marchand (1969), Bauer 
(1983, 1987, 1993)). These syntactically-oriented treatments are all either descriptively inadequate or severely disjunctive. The main difficulty for syntactic theories is that from a syntactic point of view, the set of possible referents for-ee nouns just does not seem to be a natural class: -ee nouns can refer to the participant conventionally specified by the direct object of the stem verb, as in trainee and kickee; by the indirect object, as in payee and sendee; by the object of a governed preposition, as in experimentee and laughee; by the subject of an intransitive verb, as in resignee and standee; and by the subject of a transitive verb, as in attendee and escapee. (See the full paper for a detailed survey of the attested uses of these various classes of -ee noun types.)

One particular shortcoming of all purely syntactic analyses is that they fail to account for the significant number of $-e e$ nouns which refer to participants for which there is no syntactic argument position at all. The most salient example is amputee; as mentioned by Horn (1980), the noun amputee does not refer to any argument of the verb, but rather to the possessor of the verbal direct object. That is, if a doctor amputates John's leg, the amputee is John, and not the leg. There are a number of other case which, like amputee, refer to the possessor of the direct object participant:

(22) 1831 "It might be safe to pluck it up." Safe to whom? To the plucker or the pluckee?

(23) 1861 The precise effect which it is designed to produce on the mind of the advertisee by an advertisement.

(24) 1890 The story of that day's strife would be a long one were it written at length, ...how one man did brutally twist the knee of another for a good ten minutes, and how the twistee groaned, ...

(25) 1981 [Used in a science fiction story:] An erasee was allowed six months at the institute. [That is, someone whose mind has been erased.]

(26) 1986 The party gang...had been gung ho for slitting a few throats as long as the slittees were sound asleep.

Note that the first known occurrences of twistee and pluckee are older than that for amputee. Other candidates for inclusion in this class include advertisee, alienee, appraisee, assessee, complainee, conjuree, contestee, convenee (it is a group which convenes, not the individual members), destinee, dilutee 'an unskilled or semi-skilled worker who takes a place hitherto occupied by a skilled worker', discontinuee, drainee [person involved in "brain-drain"], dumpee, expiree 'one whose term of punishment has expired; an ex-convict', invadee (it is a country which is invaded, not an individual), jestee, jokee, lunchee, plannee, politicee, puntee ['person conveyed in a punt'], revisee, and wishee.

Thus there are two main problems for a syntactic approach. First, -ee nouns seem perfectly comfortable referring to any syntactic argument position at all. Thus any purely syntactic theory which covers all of the data will be so weak that it will provide essentially no constraints on -ee formation. The second related problem comes from -ee nouns which do not correspond to any syntactic argument. If $-e e$ formation were essentially syntactic, then the apparent ability of -ee nouns to refer to participant which are not syntactic arguments would be a deep mystery. We shall see that a semantic analysis can provide a unified treatment of $-e e$ which still makes 
significant predictions, and can also provide a natural account of non-argument uses of $-e e$.

\section{Sentience}

The clearest semantic requirement which must be satisfied by an -ee noun is that its referent must be sentient. Establishing this requirement is especially important given the arguments in section 5 below, since I claim there that a use of this suffix entails a lack of volitional control on the part of the referent, and it only makes sense to consider volitional control if the referent is capable of volition in the first place.

There are, however, two closely related systematic sets of exceptions to the sentience restriction. As observed by Horn (1980) and Bauer (1983, 1987, 1993), there are a large number of recent technical terms used by formal linguists which can be thought of as referring to sentient entities only in a figurative sense (see also Levi (1978:170, n.3)). Examples include raisee, ascendee, controllee, governee, etc. Bauer traces the onset of these uses to the early days of Relational Grammar.

The second class of exceptions is subtly different: rather than referring to undergoer participants in grammatical operations, these uses refer to the referents of grammatical argument positions, that is, they are metalinguistic. Bengtsson discusses actee 'object of the action, object acted upon', which she traces back to 1908 .

Linguists who use this specialized terminology still have intuitions that unfamiliar non-linguistic-ee nouns must refer to animateentities. For instance, although squeezee can refer to the recipient of a hug, it cannot refer to a citrus rind, so that the following discourse is deviant for all speakers: *After making himself a glass of grapefruit juice, John threw the squeezees away. Furthermore, except for the sentience requirement, linguistic uses seem to adhere to the other semantic requirements argued for here. I will ignore linguistic and metalinguistic uses from now on.

\section{The episodic nature of -ee}

This section describes a second semantic constraint on -ee nouns, namely the requirement that the denotation of an -ee noun must be episodically linked to the denotation of its stem. This requirement concerns the way in which the meaning of an $-e e$ noun is related to the meaning of its verbal stem. More specifically, I will suggest that calculating the extension of an -ee noun crucially depends on identifying those individuals who participate in the events characterized by the stem verb. For example, in order to qualify as a gazee it is necessary to participate in a certain role in a gazing event.

\subsection{Qualifying events}

Clearly, in order to be more explicit about the meaning of -ee nouns we must talk about events and participants in events. And since the compositional component of the meaning of -ee nouns depends on the meaning of the verbal stem, we must first talk about verbal events. I will assume that all verbs (stative or not) can be associated with a set of particular events (or eventualities) characterized by the meaning of the verb. For an -ee noun to be applicable to an individual, (a stage of) that individual must have participated in a particular event of the type characterized by the stem predicate. Thus a typical use of an -ee noun covertly refers to a specific event. For 
example, consider the extension of the -ee noun lessee and the event type named by the stem verb lease. For every individual who is a lessee there must be a leasing event by virtue of which the individual qualifies as a lessee, and conversely, for every leasing event there is an individual who qualifies as a lessee.

It will be convenient to divide the calculation of an - $e$ e noun's extension into two steps. For now we will be concerned with identifying a set of stages of individuals which we will call a STAGE SET. In section 4.3 we will see how to reduce the stage set to a plain set of individuals (given a particular evaluation time index).

Stages will be modeled here by a pair consisting of an individual and an eventuality. More formally, the domain of discourse $D$ will be based on a set of individuals $I$ and a set of eventualities $E$. A stage is an ordered pair $\langle x, e\rangle$ where $x$ is an individual in $I$ and $e$ is an event in $E$. A temporal trace function $\tau$ maps stages onto (possibly punctual) intervals of the real number line. Note that having a set of stages in the model implicitly defines a notion of participation in an event, where an individual $x$ PARTICIPATES in an event $e$ just in case $\langle x, e\rangle$ is a stage in $D$.

I assume that every verb characterizes a set of events (or eventualities), either directly as in Neo-Davidsonian theories (in which the denotation of a verb is little more than a set of events), or implicitly in other semantic theories which recognize events. We are now in a position to define what it means to be EPISODICALLY LINKED:

(27) A derived noun $\mathrm{N}$ is episodically linked to its stem $\mathrm{S}$ iff for every stage $\langle x, e\rangle$ in the stage set of $\mathrm{N}, e$ is a member of the set of events that characterizes $\mathrm{S}$.

The proposed rule, then, is that every -ee noun must be episodically linked to its stem. For instance, for the noun lessee and the stem lease, the stage of John given by $\langle J o h n, e\rangle$ qualifies as a lessee only if $e$ is a leasing event. If so, then we can say that $e$ is a QUALIFYING EVENT for John (with respect to the predicate lessee). That is, in order for John to qualify as a lessee it is necessary for there to be a qualifying event of the appropriate event type in which John participates in the appropriate manner. Thus every leasing event qualifies some individual as a lessee, and for every lessee, there must be a leasing event which qualifies them as a lessee.

Although some deverbal nouns which are not -ee nouns do seem to be episodic, such as the concrete senses of purchase 'the thing purchased' or creation 'the thing created', it is by no means true of deverbal nouns in general that they are episodically linked to their stem verbs. Consider the noun dump in its core sense of 'a place for dumping something (as refuse)'. The following discourse is not possible: When I dumped my pencil sharpener [into the wastebasket], the dump overflowed onto the floor. That is, the mere fact that the wastebasket has participated in a dumping event does not immediately qualify it as a dump. Similarly, a single instance of consorting does not qualify someone as a consort; rather, a person is someone's consort only if they habitually consort with each other. By the same token, not every item which is presented qualifies as a present, and not every subject of the verb transport qualifies as in the extension of the noun transport. In these last three examples, note the phonological stress retraction indicating that the noun is derived from the verb.

Some of the consequences of the definitions given so far should be pointed out here. First, note that a single event can qualify more than one individual. For in- 
stance, a single conferring event can qualify any number of individuals as conferees, as long as each individual participates in the conferring event (compare consultee, convenee, meetee, and mergee).

Note that the proposed constraint governing the connection between the -ee noun and its stem is exclusively semantic, and makes no reference to any syntactic properties associated with the stem. Thus two non-equivalent predicates can be characterized by the the same event type. For instance, on some theories (but not all, e.g., Parsons (1990)), every buying event is a selling event, so the event type which characterizes the predicate denoted by buy is the same event type which characterizes the predicate denoted by sell. (On this view, then, the predicates denoted by buy and sell are semantically identical except for the order of their arguments.)

More importantly for the description of $-e e$, the fact that the episodic constraint is exclusively semantic means that, unlike the syntactically oriented accounts discussed above, there is no explicit connection between any syntactic argument position and the referent of an -ee noun. One advantage of this syntactic blindness is that the episodic constraint does not discriminate between direct object participants, indirect object participants, or other types of syntactic arguments, as long as the referents of these arguments are semantic participants in the events in question. Thus since adoptee refers to a direct object participant (John adopted the child), and payee refers to an indirect object participant (John paid the money to Mary), and gazee refers to an argument marked with a governed preposition (John gazed at Mary), on a syntactic account (as we have seen) it is necessary to postulate at least three distinct uses of $-e e$ (and more for other cases). On the semantic account here, these distinctions are not present: the referents of the different -ee nouns are all alike in being participants in the relevant events. That is, the adoptee is a semantic participant of an adoption event, the payee is a semantic participant of an paying event, and the gazee is a semantic participant of a gazing event. From the point of view of the episodic constraint, they are all three on an equal footing semantically. Thus as we will see in the next section, the semantic approach provides the key to constructing an analysis which unifies uses which must be treated separately on the syntactic account.

\subsection{Referring to non-arguments}

Another clue that -ee operates largely at a semantic level comes from predicates whose member events can systematically have participants for which there is no corresponding syntactic argument. Since syntactic argument structure is irrelevant for the semantic analysis, nothing in the semantic analysis prevents an -ee noun from selecting such a particpant as its referent. And in fact as we saw in section 2.3, there are many -ee nouns which refer to a participant for which there is no syntactic argument. Therefore it is in the favor of the semantic analysis that it explains such uses automatically without any need for further modification.

To see how the semantic explanation works for these cases in more detail, consider the syntactic arguments of the verb amputate. The subject specifies the agent participant in the amputation event, and the direct object specifies a part of some individual, the entity which is to be cut off or separated from the individual in question. Crucially, there is no syntactic position which specifies the identity of the 
individual whose limb is to be amputated. That is, it is impossible to say *The doctor amputated John or even *The doctor amputated a leg from John. Nevertheless, when we consider the set of amputation events, it seems quite natural that a reasonable theory of events should recognize the person who is undergoing the amputation as a participant in the amputation event. That is, the meaning of the verb amputate entails the existence of a person undergoing amputation, even though there is no syntactic argument which corresponds to this participant. However, the fact that the person undergoing amputation is a participant of every amputation event is sufficient to enable a set of amputation events to serve as a set of events characterizing the -ee noun amputee. Consider the set of amputation events in which the individual undergoing amputation is sentient (this will exclude figurative uses such as the evil editor amputated the appendix to my paper). For each such event $e$, there exists an individual $x$ which is a participant in $e$ such that $x$ is (becomes) an amputee. This is sufficient to satisfy the definition of episodic with respect to the relevant set of events, and thus to demonstrate that amputee (and for other similar-ee noun types mentioned in section 2) satisfies the formal constraint.

\subsection{Aspectual issues: from stages to individuals}

If the denotation of -ee nouns does in fact depend more or less directly on a set of events, this naturally raises the question of whether traditional verbal issues of aspect or aktionsarten are relevant for the semantics of -ee nouns. In the verbal domain, these factors contribute to constraints on morphological tense, constraints on possible modifiers (in an hour versus for an hour), and so on. I will argue that semantic aspectual properties of verb denotations do directly affect the behavior of -ee nouns. More specifically, whether the events associated with the stem verb are punctual or not determines the extent of the time during which an individual remains in the extension of an -ee noun. Thus a person who becomes an adoptee remains an adoptee for the rest of their life, but an individual is an employee only for the duration of their employment.

We can say that a qualifying event $e$ is punctual just in case the temporal trace function $\tau$ maps $e$ onto a point (an interval of length 0 ). I will assume that for any particular -ee noun, the set of relevant qualifying events are either all punctual or all non-punctual. Thus we can say that an-ee noun is punctual or non-punctual depending on whether the stages in its denotation all contain punctual qualifying events or not. Factors which help predict whether a particular - ee noun will be punctual or non-punctual will be discussed shortly, but first we will see how classifying -ee nouns into punctual and non-punctual determines how they behave semantically.

So far we have discussed the denotation of -ee nouns as sets of stages. Since stages have a natural association with a particular interval of time (namely, the temporal trace of its component event), we have not needed so far to consider imposing any temporal structure on our denotations. Recall that on a standard compositional semantics (e.g., Montague (1970)), the sense of a noun is a function from possible worlds and times to a set of individuals, i.e., the extension of the noun in the given world at the given time. We are now in a position to calculate the extension of an-ee noun when evaluated with respect to a particular time $t$ (we can continue to ignore intensionality): 
(28) An individual $x$ will be in the extension of an -ee noun $N$ when evaluated at time $t$ just in case there is a stage $\langle x, e\rangle$ in the stage-set of $N$ and either (1) $e$ is punctual and $\tau(e) \leq t$ or (2) $e$ is non-punctual and $t \subset \tau(e)$.

That is, if the qualifying event for $x$ is punctual, $x$ is in the extension of the -ee noun in question from the moment at which the qualifying event occurs onwards; but if the qualifying event is non-punctual, then $x$ is in the extension of the -ee noun only for the duration of the qualifying event.

For instance, Mary qualifies as a draftee from the moment she is drafted onward, and she can be felicitously described as a draftee until the description is no longer relevant or informative. Thus draftee is a punctual-ee noun, and from the point of view of the -ee noun, undergoing a drafting event constitutes a permanent change of state. Some -ee nouns in which the permanence of the change of state is particularly salient include adoptee, amputee, divorcee, inductee, patentee, retardee, and retiree.

In contrast, John qualifies as an employee only for as long as he is employed. I assume that the employment event which qualifies John as an employee has a nonpunctual duration, and John the individual will be in the extension of employee only at those times which fall within the temporal trace of the employment event. To see this, note that if John has been employed as a baker for several years but is suddenly fired, he is still a baker (John is an unemployed baker), but he is no longer an employee (*John is an (unemployed) employee).

What determines whether an -ee noun will be punctual or non-punctual? The basic generalization seems to be that the punctuality of the denotation of an -ee noun follows from the semantics of the stem verb in combination with the requirement that an -ee noun must be episodically linked to its stem.

Some verbs characterize events which are naturally punctual. For instance, the action described by the verb dedicate (in the sense of dedicating a book) is essentially punctual. It is not possible to dedicate a particular book for several months. Therefore we can assume that all of the qualifying events available to form members of the denotation of dedicatee 'person to whom a book is dedicated' are punctual. As a consequence, we correctly predict that a person is in the extension of the -ee noun from the moment at which the dedication occurs on. Other-ee nouns whose stem verb seem to be naturally punctual include appellee, delegatee, photographee, selectee, surrenderee, and many of the violent series such as hitee, kickee, murderee, etc.

It should be noted, however, that even if these punctual -ee nouns denote properties which remain true of an individual forever, it will only be cooperative to use such a noun to describe an individual for as long as the qualifying event continues to be sufficiently salient and relevant, and only so long as there is no other description which is more appropriate. Thus a person will be described as a hitee only if the speaker can assume that the listener is aware of the relevant hitting event. Similarly, a person will be described as an adoptee only in a context in which their status as an adoptee has a significant impact on their life, as shown by the many attested occurrences of the expression adult adoptee, which is not someone who was adopted as an adult but rather someone who participated in an adoption event as a young child and who has since grown to adult age. Also, a person will be described 
as a nominee only until the nomination has been confirmed or rejected (to see that the individual nevertheless continues to qualify as a nominee, note that it is peculiar to describe someone as a former nominee).

Some-ee nouns such as expiree 'one whose term of punishment has expired; an ex-convict' are derived from stem verbs which are not inherently punctual but which nevertheless present a gradual process as if it occurred at a particular moment, and which result in punctual -ee nouns. Other potential examples in the same class include curee, civilizee, educatee, and recoveree.

Other verbs characterize events which are naturally non-punctual. For example, just as for the noun employee (discussed above), the action described by the verb borrow necessarily occurs over some non-punctual interval of time. This observation leads to the prediction that someone ceases to be a borrowee after the item in question has been returned. Similarly, a person is in the extension of trainee only during their training. Additional examples include standee, secondee, sitee, relaxee, tutee, waitee, and so on. Legal -ee nouns are also typically non-punctual, and the temporal trace of the relevant qualifying events coincide with the interval that the legal obligation is in force. For example, a person qualifies as a lessee only during the term of the rental contract. Similarly for pawnee, bailee, pledgee, creditee, vouchee, loanee, and so on.

Although the brief comments in this subsection are far from a complete account of the relationship between verbal aspect/aktionsarten and the semantics of -ee nouns, I hope that they establish several important points: (1) some-ee nouns have an individual in their extension from some moment onward (punctual -ee nouns), and some -ee nouns have particular individuals in their extension only for limited periods of time (non-punctual -ee nouns); (2) whether an -ee noun will be punctual or non-punctual is systematically related to semantic properties of the stem verb; and (3) the hypothesis that -ee nouns are episodically linked to their stem verbs provides an explanation for how the punctuality of an -ee noun depends on the semantics of its stem verb.

\section{Lack of volitional control}

This section takes seriously the commonplace intuition that the meaning of -ee has a component which is very much like a thematic relation. For example, a common impression is that -ee nouns typically refer to people who have had something bad happen to them: amputee, hittee, refugee, etc. all refer to people who would presumably have been better off not participating in the event which qualifies them as -ee noun referents. However, there are a large number of -ee nouns which are more neutral as to the desirability of their applicability (addressee, franchisee, lessee, pollee), and a significant number of -ee nouns whose referents should be supposed to be quite happy to participate (honoree, nominee, lovee, etc.).

Perhaps it would be better to use Bolinger's (1941) terminology; he says that -ee denotes not a passive meaning, but "passivity". Many authors (e.g., Baayen and Lieber (1991:820)) describe episodic -ee as a 'patient' suffix, and, as mentioned above, Horn (1980:142) asserts (without further elaboration) that "the animate -ee nominal is presented as helpless or relatively powerless". These clues suggest that what is common to all of these uses is that they either entail or are consistent with 
the notion that the -ee participant undergoes the event, whether favorable or not, without being in control, or at least with limited or reduced control. The specific constraint that will be defended here is as follows:

(29) The use of an -ee noun entails a lack of volitional control on the part of its referent either over the occurrence or the duration of the qualifying event itself or (given a punctual qualifying event) over its immediate direct consequences.

The best way to make the intention of this rule as clear as possible will be through discussion of a number of examples.

This constraint is most clear for the malefactive uses, of course. In the neutral uses, note that no consent is required in order to become an "addressee", especially for the common use in which the addressee is the person that a letter or a package is addressed to. Similarly, franchisees, honoree, lessees, nominees, lovees and pollees, however eager they may be, must first be selected by someone else before their respective qualifying events can occur.

The larger semantically coherent subgroups of $-e e$ nouns clearly fall within the domain of compulsion and obligation. The essence of the core legal uses of -ee, of course, is obligation under the law. Some examples include appellee, debtee, divorcee, donee, evictee, feoffee, garnishee, lessee, obligee, pledgee, trustee, and warrantee. There are 74 attested word types which are clearly entail that the -ee participant has specific legal obligations as a result of participating in the qualifying event.

Clusters of -ee noun uses occur in other domains in which compulsion or obligation is highly prominent. Some of the more prominent include actions related to personal violence: 33 examples, including beatee, fuckee, hittee, kickee, knockee, punchee, slittee, sockee, torturee, twistee, and vivisectee; crime and police work: 17 examples, including abductee, arrestee, blackmailee, cheatee, followee, muggee, murduree, and tailee; prisons and punishment: 12 examples, including escapee, expiree, floggee, offendee, pardonee, parolee, and releasee; military and war: 17 examples, including bombee, deferee, draftee, enlistee, invadee, pillagee, selectee, shavee, and surrenderee; humor: 10 examples, viz. amusee, banteree, gaggee, geggee, hoaxee, jestee, jokee, laughee, roastee, and teasee; business: 28 examples, including acquiree, bargainee, contractee, employee, firee, franchisee, optionee, sweatee, and tenderee; politics, government and bureaucracy: 20 examples, including asylee, electee, evacuee, persecutee, pollee, refugee, restrictee, and returnee; social norms: 30 examples, including affrontee, boree, cursee, cuttee, handshakee, introducee, socializee, toastee, and visitee; education: 17 examples, including advisee, crammee, enrollee, examinee, exchangee, ment(or)ee, passee, pledgee, rushee, testee, tryoutee, and tutee; publishing: 9 examples, viz. biographee, citee, dedicatee, editee, festschriftee, publishee, quotee, revisee, and writee; communication: 25 examples, including addressee, communic(at)ee, describee, explainee, gazee, leakee, narratee, readee, talkee, writee, and yellee.

Finally, last but not least, there are the technical linguistics terms, which uniformly appeal to figurative compulsion and manipulation of grammatical objects: 20 examples, viz. actee, advancee, ascendee, benefactee, causee, cliticee, controllee, deletee, determinee, dislocatee, draggee, eliminatee, erasee, extractee, forcee, gov- 
ernee, malefactee, piedpipee, possessee, and reorderee.

\section{1 -Ee nouns which refer to stem verb subjects}

What about -ee nouns which refer to qualifying event participants which are typically specified by the subject of the stem verb? Since subjects are typically highly agentive and most of ten in control of the verbal event, it seems unlikely that they would be good candidates for -ee noun referents. However, as we saw in section 2.2 , there are many such -ee nouns. Since this class of -ee nouns is one of the most problematic for the various syntactic hypotheses, it is especially important to see how well the semantic hypothesis accounts for them. The semantic explanation offered here has two parts: in some cases, although the qualif ying event itself is under the control of the -ee participant (as befitting a verbal subject), there is a clear lack of control over the direct consequences of the event, and the use of the -ee form emphasizes this lack of control; and in other cases, there may be strong entailments showing that even though the -ee participant is an active participant, their actions are nevertheless compelled or constrained by external forces independently of any entailments that are part of the meaning of the stem. We will consider these two types of cases in turn.

Usually the -ee participant lacks control over the occurrence of the qualifying event itself. For instance, a toastee will be the recipient of a toast whether she wants to be or not. Similarly, a deferree will be able to succeed at deferring their military service only with the cooperation of their draft board. However, it is also possible for a lack of control to occur subsequent to the onset of the qualif ying event. In such cases the -ee participant may be in control concerning whether or at least when the qualifying event will occur, but as a result of the event itself becomes subject to substantial constraints on his or her actions which are no longer under their volitional control. Many legal uses fall in this category. A leasing event can occur only at the discretion of the lessor; but by entering into a lease it is also necessary for the lessee to agree to the terms of the contract as well. Once the contract is in force the lessee is obligated to perform in a certain fashion for the remainder of the duration of the leasing event. Other similar examples include bailee 'one to whom goods are committed in trust for a specific purpose', pawnee 'the person with whom something is deposited as a pawn or pledge', and exchangee 'a participant in an exchange program'.

The notion that voluntarily submitting oneself to obligations can constitute a lack of control is crucial to understanding those cases which must be most difficult to any purely syntactic theory of $-e e$, namely, those cases in which the -ee noun refers to the subject of the stem verb and especially those cases in which the stem verb is unergative rather than unaccusative.

Certainly the most famous example of this type is escapee. An escapee is volitionally, actively, and deliberately causally involved in bringing about the escaping event, and thus is for the most part in control of whether and when an escaping event will occur. However, once the escape has been effected, the escapee undergoes a significant and relevant change of state, one result of which is that he or she is subject to consequences that are quite certainly not in their control and in fact which are quite strongly negative, including pursuit, recapture, and punishment for escaping. Thus 
escapee has come to be nearly synonymous with fugitive.

Note that in the cases of entering into a legal contract, the subsequent lack of control on the part of the -ee participant occurs entirely during the qualif ying event. However, as shown by escapee, when the qualifying event is punctual, it is possible that the qualif ying event merely serves as the beginning point (both temporally and causally) of the period of lack of control. Other noun types worth considering here include resignee, retiree, attendee, enlistee, enrollee, and returnee; see the full paper for discussion. Another cogent possibility (suggested to me by David Dowty) is that the relevant period of lack of control occurs before the event, in the circumstances which compelled the person to escape, to resign, to retire, etc.

The most striking examples of -ee nouns used to refer to a verbal subject, however, come from what seem to be productive uses. The data strongly support the idea that $-e e$ forms are more likely to be used (rather than, say, productive episodic -er forms) when the context emphasizes some way in which the referent lacks volitional control. The following list contains all examples from my corpus of $1500-e e$ noun occurrences involving -ee nouns that have a single attested occurrence (i.e., are relatively rare), and in which the -ee noun refers to the subject participant of a stem verb event. I assume that most or all of them are either productive uses (nonce formations) or uses of recently coined or newly-reinvented types (recent relative to the use quoted).

(30) 1617 Touching these submitties while they were in rebellion, he did spoile waste and kill many of them.

(31) 1935 "I was a fool to marry a man like you", she continued, her eyes averted,"I ought to have known better. Oh, it's a tribute to you and not a reproach... There are some women who are mergers and others who aren't. I'm like you-a mergee."

(32) 1945 Keys for Forgettees [sign over a desk in the reception Section of the Pentagon Building at Washington, D.C.]

(33) 1957 There was the Asian influenza casualty.... who was replaced gallantly by an influenza recoveree, $\mathrm{Mr}$ Robert Harben.

(34) 1968 A weightless embarkee would reel before a sudden gust, fall, and be blown about the quay.

(35) 1970 Some meetings should be...mercifully brief. A good way to handle the latter is to hold the meetings with everybody standing up. The meetees won't believe you at first. Then they get very uncomfortable and can hardly wait to get the meeting over with.

(36) 1971 [Experiment involving shining lights into subject's eyes.] The adaptee then cannot tell the difference between yellow and white, i.e. is yellow-blind.

(37) 1977 The NP...that is moved by an ascension rule we will refer to as the 'ascendee'.

(38) 1978 We didn't have any way of accurately estimating how many standees and sitees we had, but I think one hundred would be a conservative estimate.

(39) 1980 [In the doctor's waiting room:] Sketch your fellow waitees.

(40) 1987 These young musicians were chosen from over 200 auditionees...

(41) 1988 Life after a merger tends to be less pleasant when you're the "mergee," or weaker party... 
(42) 1989 In Mamet's equally brief one-acter, the devil-called the interrogatorharasses a new arrivee named Bobby Gould in an anteroom to hell that looks like a well-appointed study.

(43) 1993 Another device DeKoven uses is the Meetings Meter, a piece of software that functions like a taxi meter, displaying a continuing tally on how much the meeting is costing. The inspiration for the device came at a meeting with his attorney when DeKoven realized he wasted $\$ 11$ telling a long joke to the $\$ 300$ an-hour laughee.

(44) 1993 The ground rules were simple: to find ways to relax that required absolutely no effort on the part of the relaxee, i.e. stress reduction strictly by pampering.

(45) 1994 The detective on the case is John Becker, a former FBI agent and a returnee from two previous novels by the same author.

(46) 1994 The paella didn't turn out very well, but fortunately my dinees were quite understanding.

(47) 1994 [A radio announcer discusses a device which] would go off if the offendee left the house.

In each case the context of use establishes special circumstances which add or emphasize a lack of volitional control or a relinquishing of control on the part of the otherwise highly agentive referents. For instance, although in general adapting is usually a highly intentional process, here adapting to a bright light is an involuntary reflex of the human eye (i.e., involuntary on the part of the referent of the-ee noun). Similarly, although arriving is usually the intended goal of an agent, the quoted use emphasizes the lack of control of the arrivee over the consequences of arriving, since arriving subjects him to the torments of the devil. A laugher can be described as a laughee when he has been forced or induced or expected to laugh. And finally, although diners are almost always highly active, agentive, and in control, there are times when aggreeing to dine at someone's house commits the diner to experiencing a meal which they might have preferred to avoid (the use of the possessive construction further emphasizes that the diners have relinquished control to their host).

These examples pose a particularly difficult problem for a purely syntactic theory, unless the syntactic properties of verbs are allowed to vary from one use to another depending on semantic factors present in the context.

In summary, lack of volitional control is a strong element in virtually all established uses, and, more important for the main purposes of this paper, seems to actively constrain productive uses of the suffix, i.e., coinages and nonce formations.

\section{Viewing the semantics of $-e e$ as a thematic role type}

Do the semantic constraintsargued for above amount to a thematic relation? A clear answer would be possible only if the notion of a "thematic relation"itself were clear, which it isn't. As a starting point, Dowty (1989:77) suggests that a thematic role type minimally is a non-trivial set of semantic entailments which (partly) characterizes a natural class of argument positions. Assuming that the set of all -ee nouns is a natural class, then the semantics of -ee qualifies as a thematic role type at least according to this definition. 
Traditional thematic relations such as Agent, Patient, Goal, etc., are crucially connected to events. That is, they specify some aspect of the way in which the entity they are associated with (the referent of the argument which bears the thematic relation) participates in a particular event. Because -ee nouns are episodically linked to their stem verbs, the semantic constraints on -ee are event-related in the same way: they specify the manner in which the referent of an -ee noun participates in its qualifying event. This is in contrast to more stative thematic relations typically said to hold of other concrete nouns, or more abstract nominal relations such as the possession relation.

There is at least one important respect in which the semantic constraints on $-e e$ do not parallel traditional thematic relations. Typically, thematic relations come in sets, and interact with linguistic generalizations only in opposition to one another (Agent versus Patient in argument selection, obliqueness hierarchies, etc.). At least at this stage, it is not obvious that there is any independently motivated system of nominal thematic relations from which the thematic role associated with $-e e$ is taken.

In any case, the existence of $-e e$ shows that the argument structure of a deverbal derived noun cannot be reliably predicted in general based only on the syntactic argument structure of its verbal stem. Furthermore, since -ee seems to be productive, if the semantic entailments in question do indeed constrain formation of new $-e e$ nouns, then they must be part of a native speaker's active knowledge of their language.

\section{References}

Aronoff, Mark (1976) Word Formation in Generative Grammar, MIT Press, Cambridge, Massachusetts.

American Heritage Dictionary, 2nd Edition (1982), 3rd Edition (1991), Houghton Mifflin, Boston.

Barker, Chris and David Dowty (1993) 'Non-verbal thematic proto-roles', in Amy Schafer, ed., proceedings of NELS 23, GSLA, Amherst.

Barnhart, C. L., S. Steinmetz and R. K. Barnhart (1973) A Dictionary of New English, Longman, London.

Barnhart, Robert K., Sol Steinmetz, and Clarence L. Barnhart, eds., (1990) Third Dictionary of New English, H. W. Wilson Company, [no city].

Bames, Matthew (1928) 'Words from the French (-E, -ee)', SPE Tract XXX, 298305.

Bauer, Laurie (1983) English Word-Formation, Cambridge University Press, Cambridge, $243-250$.

Bauer, Laurie (1987) ‘-EE by gum!', American Speech 62.4, 315-319.

Bauer, Laurie (1993) 'More -EE words', American Speech 68.2, 222-224.

Baayen, H. and R. Lieber (1991) "Productivity and English Derivation: A CorpusBased Study", Linguistics 29, 801-843.

Bengtsson, Elna (1927) Passive nouns with a concrete sense in English, Häkan Ohlsson, Lund.

Bernstein, Theodore M. (1977), Do's, Don'ts and Maybes of English Usage, Times Books, New York. 
Bollinger, Dwight L. (1941) 'Among the New Words', regular column in American Speech, 16.4 (December), repreinted in John Algeo, ed., (1991) Fifty Years Among the New Words, Cambridge University Press, Cambridge, page 90.

Carlson, Greg (1982) 'Generic terms and generic sentences', Journal of Philosophical Logic 11:145-181.

Carlson, Greg (1984) 'Thematic roles and their role in semantic interpretation', Linguistics 22:259-279.

Chomsky, Noam (1970) 'Remarks on Nominalization', in Readings in Transformational Grammar, Roderick Jacobs and Peter Rosenbaum, eds, Waltham, Massachusetts, 184-221. Also in Noam Chomsky (1972) Studies on Semantics in Generative Grammar, Mouton, The Hague, 11-61.

Dowty, David (1989) 'On the Semantic Content of the Notion of 'Thematic Role', in Gennaro Chierchia, Barbara H. Partee, and Raymond Turner, eds., Properties, Types, and Meaning II, Kluwer, Dordrecht, 69-129.

Dowty, David (1991) 'Thematic proto-roles and argument selection', Language 67.3:547-619.

Enç, Mürvet (1981) Tense Without Scope: An Analysis of Nouns as Indexicals, $\mathrm{PhD}$ Dissertation, University of Wisconsin-Madison.

Follet, Wilson (1966) ModernAmerican Usage, Jacques Barzun, ed., Hill and Wang, New York.

Foster, Brian (1968) The Changing English Language, Macmillan, London.

Fowler, Henry (1965) A Dictionary of Modern English Usage, Sir Ernest Gowers, ed., Clarendon, Oxford.

Grimshaw, Jane (1990) Argument Structure, MIT Press, Cambridge, Massachusetts.

Gupta, Anil (1980) The logic of common nouns: an investigation of quantified modal logic, Yale University Press, New Haven.

Harder, Kelsie B. (1964) 'The Suffix "-ee", American Speech 39, 294-6.

Horn, Laurence R. (1980) 'Affixation and the Unaccusative Hypothesis', Proceedings of the Chicago Linguistics Society, volume 16, 134-146.

Jespersen, Otto (1905) Growth and Structure of the English Language, B. G. Teubner, Leipzig.

Jespersen, Otto (1942) A Modern English Grammar on Historical Principles, Part VI (Morphology), section 13.6, 220-2.

Koziol, H. (1972) Handbuch der englischen Wortbildungslehre, Carl Winter Universita"tsverlag, Heidelberg. 2 Auflage [2d edition?]

Krifka (1990) 'Four thousand ships passed through the lock: object-induced measure functions on events', L\&P 13: 487-520.

Kruisinga, E. (1932) A Handbook of Present-Day English, volume 3, fifth edition, P. Noordhoff, Groningen.

Levi, Judith (1978) The Syntax and Semantics of Complex Nominals, Academic Press, New York.

Marchand, Hans (1969) The Categories and Types of Present-Day English WordFormation, C. H. Beck, Munich.

McAtee, W. L. (1945) 'Irradiations of the Suffixes '-EE' and '-EER', American Speech 20, 75-6.

Mencken, H. L. (1967), The American Language, Knopf, New York. 
Oxford English Dictionary, second edition (1992), Oxford University Press, Oxford. Montague, R. (1970) 'The Proper Treatment of Quantification in English', in J. Hintikka, J. Moravcsik, and P. Suppes, eds., Approaches to Natural Language: Proceedings of the 1970 Stanford Workshop on Grammar and Semantics, Reidel, Dordrecht, 221-42. Also in R. Thomason, ed., (1974) Formal Philosophy: Selected Papers of Richard Montague, 247-270.

Morris, William and Mary Morris (1985), Dictionary of Contemporary Usage, second edition, Harper and Row, New York.

Onions, C. T. (1943) 'The Fate of French $-e$ ' in English', Society for Pure English (SPE) Tract LXI.

Parsons, Terrence (1990) Events in the Semantics of English, MIT Press, Cambridge, Massachusetts.

Perlmutter, David (1978) 'Impersonal Passives and the Unaccusative Hypothesis', Proceedings of the Berkeley Linguistics Society 4.

Person, Henry A. 1958, 'Ware the Escapee', Word Study 34, 1958, page $6 \mathrm{ff}$.

Pyles, Thomas (1952) Words and Ways of American English, Random House, New York. [Also published in 1954 by Andrew Melrose, London.]

Rappaport, Malka (1983) 'On the Nature of Derived Nominals', Papers in Lexical Functional Grammar, L. Levin, M. Rappaport, and A. Zaenen, eds., Indiana University Linguistics Club, Bloomington.

Rosen, Carol (1984) 'The interface between semantic roles and initial grammatical relations', in David Perlmutter and Carol Rosen, eds., Studies in Relational Grammar 2, University of Chicago Press, Chicago, 38-77.

Safire, William (1982) What's the Good Word?, Times Books, New York.

Stein, G. (1973) English Word-Formation over two Centuries, Ben jamins, 189-90.

Urdang, Laurence, Alexander Humez, and Howard G. Zettler, eds., (1982) Suffuxes and Other Word-Final Elements of English, Gale Research Company, Detroit. 